\title{
The Predictive Value of the Hydrogen Breath Test in the Diagnosis of Fructose Malabsorption
}

\author{
Ulf Helwiga, Anna K. Koch ${ }^{c, d}$ Nadine Koppka ${ }^{a}$ Sylvia Holtmann ${ }^{a}$ \\ Jost Langhorst ${ }^{c, d}$
}

${ }^{a}$ Medical Practice for Internal Medicine Oldenburg, Oldenburg, Germany; ${ }^{b}$ Department of Internal Medicine, Christian-Albrechts University Kiel, Kiel, Germany; ' Department of Integrative Gastroenterology, Kliniken

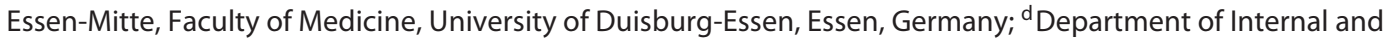
Integrative Medicine, Kliniken Essen-Mitte, Faculty of Medicine, University of Duisburg-Essen, Essen, Germany

\section{Keywords}

Fructose malabsorption diagnosis · Hydrogen breath test . $\mathrm{H}_{2}$-exhalation · Fructose-free diet · Irritable bowel syndrome

\begin{abstract}
Background: Fructose malabsorption is commonly diagnosed by the hydrogen fructose $\left(\mathrm{H}_{2}\right)$ breath test. However, the mechanisms behind fructose malabsorption in humans are not well understood and the clinical relevance of this test is considered controversial. Hence, the main aim of this study is to evaluate the predictive value of the $\mathrm{H}_{2}$ breath test. Methods: Regarding exclusion criteria, the study enrolled 562 consecutive patients, enlisted to a gastroenterology clinic between 2009 and 2011 for testing malabsorption. In the final data analysis, 246 patients were included. Ecotrophologists used 3 categories to rate dietary success: complete response, partial response and no response to the diet. They also rated the occurrence of abdominal pain, diarrhoea and bloating during the $\mathrm{H}_{2}$ breath test. Ordinal regression analysis using SPSS was performed to evaluate whether $\mathrm{H}_{2}$ breath test results - measured as the maximum $\mathrm{H}_{2}$ level, the maximum increase in $\mathrm{H}_{2}$, and the area under the curve (AUC) - predicted dietary success or failure. Correlation anal-
\end{abstract}

yses were applied to test whether symptoms of fructose malabsorption correlated with the $\mathrm{H}_{2}$ breath test measures. Finally, we evaluated whether cut-off-values of 40 or 60 parts per million (ppm) serve better than the test measure of $20 \mathrm{ppm}$ to diagnose fructose malabsorption. Results: When a fructose-free diet was administered it was found that 103 patients $(41.9 \%)$ were complete responders, 116 (47.2\%) were partial responders and 27 (11\%) were non-responders. The $\mathrm{H}_{2}$ breath test with the 20 ppm cut-off-value, that is, the maximum $\mathrm{H}_{2}$ level, the maximum increase in $\mathrm{H}_{2}$, and the AUC did not predict dietary response (all $95 \% \mathrm{Cl} \mathrm{ns).}$ This was also the case when using 40 or 60 ppm as cut-offvalues (all $95 \% \mathrm{Cl} n s$ ). Abdominal pain during the test correlated significantly with the AUC. Diarrhoea and bloating correlated significantly with the AUC, the maximum $\mathrm{H}_{2}$ level and the maximum increase in $\mathrm{H}_{2}(p<0.05)$. Conclusions: The $\mathrm{H}_{2}$ breath test produced no predictive value for the fructosefree diet outcomes; its value as a predictive test is therefore questionable. However, the symptoms of fructose malabsorption correlated significantly with the $\mathrm{H}_{2}$ breath test measures, and this is an indication that there is at least a degree of validity of the $\mathrm{H} 2$ breath test beyond the simple detection or exclusion of fructose malabsorption.

(c) 2018 S. Karger AG, Basel

\section{KARGER}

(C) 2018 S. Karger AG, Basel 


\section{Introduction}

Primary fructose malabsorption is a highly prevalent disorder and a frequent gastrointestinal diagnosis. It ranges from 38 to $80 \%$, depending on the diagnostic fructose dose, in patients with unexplained gastrointestinal symptoms tested in a gastroenterology clinic [1-3]. While fructose intolerance is characterized by an inherent liver enzyme defect, primary fructose malabsorption is probably marked by an ineffective monosaccharide transportation system in the small bowel. In affected patients, this incomplete absorption of fructose causes potential problems like flatulence, diarrhoea and abdominal pain. In healthy people, carbohydrates are digested and reabsorbed via the brush border of the small bowel [4]. In patients with fructose malabsorption, it is assumed that the absorption of fructose is impaired and this leads to a higher concentration of fructose in the colon. In the colon, fructose is metabolized by bacteria to short-chain fatty acids, hydrogen and methane, and this leads to flatulence and diarrhoea $[5,6]$. Besides the primary fructose malabsorption described above, there is also secondary fructose malabsorption. In cases of inflammation of the upper small intestine such as Morbus Whipple, Coeliac or Crohn's Disease, or acute infectious diseases, the malabsorption is caused by a destruction of the membrane, and is therefore called secondary malabsorption [7]. Causes of this type of fructose malabsorption are different from the causes of primary fructose malabsorption. The focus of this paper lies in primary fructose malabsorption.

Primary fructose malabsorption is commonly diagnosed by a hydrogen fructose $\left(\mathrm{H}_{2}\right)$ breath test [7]. The $\mathrm{H}_{2}$ breath test is the standard test in daily patient care. With the high rates of gastrointestinal complaints and the high prevalence of fructose malabsorption, physicians frequently apply this test. However, it has not been well evaluated. A better understanding of the test would be helpful in the following areas of work: the physicians' work, medical advice and the administration of the $\mathrm{H}_{2}$ breath test in daily care. The test rationale is that bacteria metabolize the unabsorbed fructose producing $\mathrm{H}_{2}$ as a by-product. $\mathrm{H}_{2}$ is then reabsorbed and excreted through the breath, where it can be easily measured. An increase from the baseline of more than 20 parts per million (ppm) of the $\mathrm{H}_{2}$ concentration in the exhaled air is seen as a significant increase, which justifies the diagnosis of fructose malabsorption [8-10]. This significance value has been extrapolated from the lactose breath test. Evidence of the correct diagnosis is a clinical improvement after fructose reduction. A fructose-restricted diet should improve symptoms of fructose malabsorption, but to date it is unclear whether the $\mathrm{H}_{2}$ breath test does predict this improvement. Therefore, the main aim of the study was to evaluate the predictive value of the $\mathrm{H}_{2}$ breath test on the clinical response of patients diagnosed with fructose malabsorption. It was expected that the higher the $\mathrm{H}_{2}$ breath test measures were, the better the response to the fructose-free diet would be. Hence, we tested whether 3 common measures of the $\mathrm{H}_{2}$ breath test - the maximum $\mathrm{H}_{2}$ level, the maximum increase in $\mathrm{H}_{2}$ and the area under the breath test curve (AUC) - predict the same response to a 10-day fructose-free diet as that rated by the patient.

Furthermore, patients with fructose malabsorption experience symptoms of bloating, abdominal pain and diarrhoea. A significant relationship between the main symptoms of fructose malabsorption, (bloating, abdominal pain and diarrhoea) and the $\mathrm{H}_{2}$ breath test measures, (the maximum $\mathrm{H}_{2}$ level, the maximum increase in $\mathrm{H}_{2}$, and the AUC) during testing would support the diagnostic value of the test.

Additionally, as the significance value of $20 \mathrm{ppm}$ to diagnose fructose malabsorption is extrapolated from the lactose breath test, there might be other, more appropriate cut-off values. Hence, we tested whether 40 or 60 ppm might serve as a better cut-off value in predicting dietary response.

To conclude within the present study, we evaluated the predictive value of the $\mathrm{H} 2$ breath test by testing 3 research questions (RQ):

RQ 1: Do the H2 breath test results predict dietary response?

RQ 2: Do the H2 breath test results correlate with symptoms of fructose malabsorption?

RQ 3: Is the significance value of $20 \mathrm{ppm}$ the most adequate cut-off value?

\section{Methods}

Design

The present study involved a non-interventional data collection, approved by the Ethical Committee of Lower Saxony, Hannover, Germany and was performed in concordance with the Helsinki Declaration.

\section{Patients}

Five hundred sixty two consecutive patients, admitted to an out-patient clinic for Internal Medicine between 2009 and 2011, who fulfilled the inclusion and exclusion criteria were tested for fructose malabsorption, participated in the study. 
Fig. 1. Study overview.

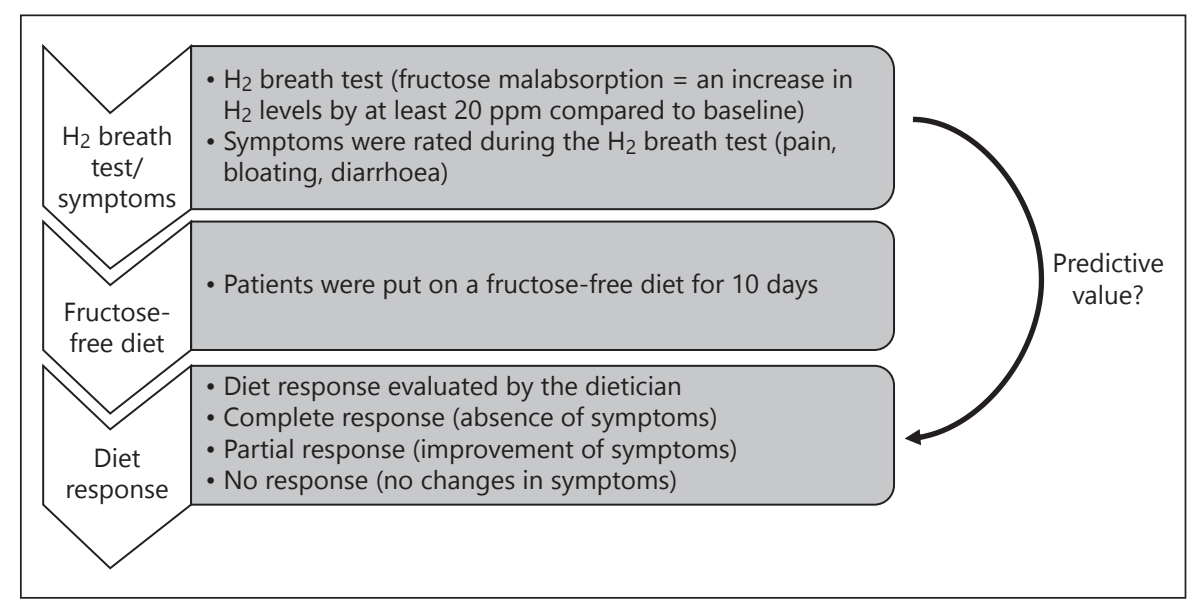

Diet

Patients diagnosed with fructose malabsorption were consulted by an experienced Ecotrophologist and put on a fructose-free diet for 10 days. Dietary instructions were given in a face-to-face manner. Fruits with high fructose content and products enriched with fructose were excluded. Adherence to the diet was determined by a daily log in which patients documented all meals. At the end of the diet an Ecotrophologist evaluated the dietary success using a standardized questionnaire.

The following categories were used to define dietary response at the end of the fructose fasting period: complete response, defined as the absence of symptoms; partial response, defined as the improvement of symptoms; and no response, indicated by no changes in symptoms.

\section{Exclusion Criteria}

Patients with secondary causes of fructose malabsorption, (gastritis or duodenitis, coeliac disease, Crohn's disease, ulcerative colitis, liver disease, pancreatic disease and lymphatic disease) and patients who also had lactose malabsorption were diagnosed and excluded from the analysis. In addition, patients with other reasons for gastrointestinal disorders (i.e., pancreas or liver disease, inflammatory bowel disease, food allergy) and non-compliant patients detected by the Ecotrophologist, who screened the nutrition protocol, were excluded. Patients who did not show clinical symptoms of fructose malabsorption (i.e., bloating, diarrhoea or abdominal pain) were identified as false positive responders and also excluded from the analysis.

\section{Diagnostic Procedures}

$\mathrm{H}_{2}$ Breath Test

Fructose malabsorption was determined by the $\mathrm{H}_{2}$ emission levels in the breath, measured by the $\mathrm{H}_{2}$ breath test at the beginning of the study before the 10-day diet. $\mathrm{H}_{2}$ emissions indicate failure of the gastrointestinal tract to absorb the fructose. It was measured as the amount of end-expiratory $\mathrm{H}_{2}$ levels in the breath before and after the ingestion of a specific amount of fructose $(50 \mathrm{~g}$ fructose diluted in $250 \mathrm{~mL}$ water). Measurements were conducted after an overnight fasting period of at least $10 \mathrm{~h}$. Patients were not allowed to take any medication or to use toothpaste prior to the test. $\mathrm{H}_{2}$ concentrations were determined at 15-min intervals for $3 \mathrm{~h}$ in total using the Gastrolyzer Breath $\mathrm{H}_{2}$ Monitor (Bedfont Scientific LTD,
ME1 3QX, England). Fructose malabsorption was defined as an increase in $\mathrm{H}_{2}$ levels by at least $20 \mathrm{ppm}$ compared to baseline. Peak $\mathrm{H}_{2}$ concentrations, areas under the curve and the maximum increase of $\mathrm{H}_{2}$ were determined for each patient.

\section{Lactulose Test}

In order to identify false non-responders and to determine the orocecal transit time we performed an $\mathrm{H}_{2}$ breath test with lactulose ( $10 \mathrm{~g}$ lactulose diluted in $100 \mathrm{~mL}$ water). The $\mathrm{H}_{2}$ breath test was performed as described above.

\section{Lactose Test}

In order to identify and exclude patients with additional secondary lactose intolerance, we performed an $\mathrm{H}_{2}$ breath test with lactose (50 g lactose diluted in $300 \mathrm{~mL}$ water). The $\mathrm{H}_{2}$ breath test was performed as described above.

\section{Symptoms}

A 4-point scale was used to determine the subjective severity of bloating, abdominal pain and diarrhoea during the $\mathrm{H}_{2}$ breath test, with the following ratings: $0=$ no symptoms, $1=$ slight symptoms, $2=$ moderate symptoms and $3=$ severe symptoms. See Figure 1 for a study overview.

\section{Data Analysis}

All analyses were performed using the Statistical Package for Social Sciences software (IBM SPSS Statistics for Windows, version 22.0). For hypothesis testing, ordinal regression and nonparametric correlation analyses were performed. For all analyses when not indicated otherwise, bootstrapping drawing 5,000 bootstrapsamples were used and the level of statistical significance was set at $p=0.05$.

\section{Results}

From 562 patients tested for fructose malabsorption, 338 were positive for fructose malabsorption (66.5\%). Seventy patients were also tested positive for lactose malabsorption and were excluded from the analysis. In 7 pa- 
Fig. 2. Flowchart of patient numbers: tested, excluded, analysed and the response rates.

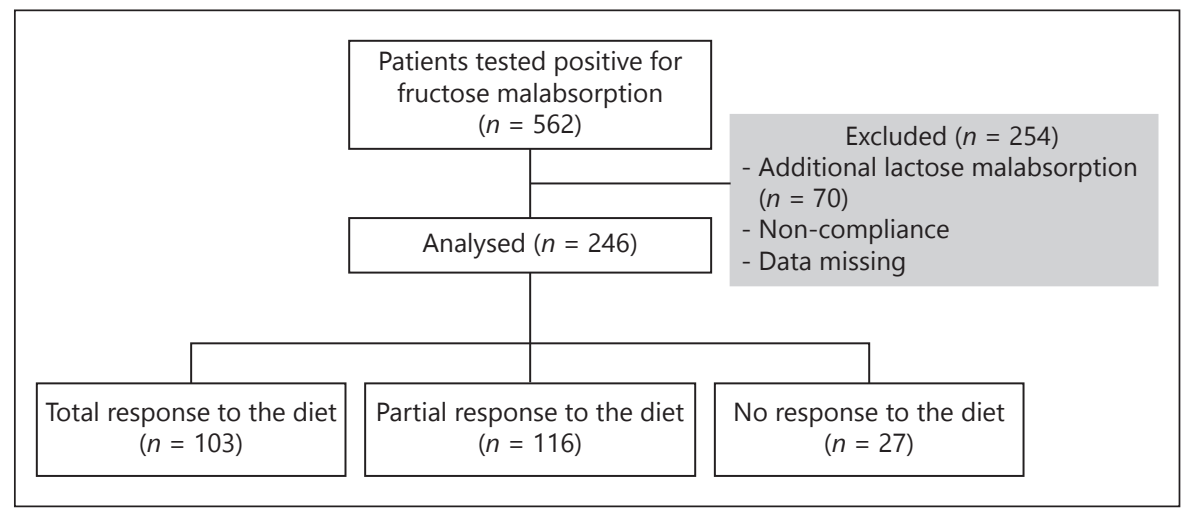

Table 1. Sociodemographic characteristics of the study sample

\begin{tabular}{lcccc}
\hline & $\begin{array}{l}\text { Total } \\
(n=246)\end{array}$ & $\begin{array}{l}\text { No response } \\
(n=27)\end{array}$ & $\begin{array}{l}\text { Partial response } \\
(n=116)\end{array}$ & $\begin{array}{l}\text { Total response } \\
(n=103)\end{array}$ \\
\hline Gender, f/m & $202 / 44$ & $22 / 5$ & $95 / 21$ & $84 / 19$ \\
Age, years $(\mathrm{M} \pm \mathrm{SD}$, range) & $39.21 \pm 18.08$ & $50.7 \pm 19.9,14-82$ & $40.0 \pm 18.4,8-83$ & $35.6 \pm 15.9,5-77$ \\
\hline
\end{tabular}

$\mathrm{f}$, female; m, male; $\mathrm{M}$, mean; no bootstrapping was applied.

Table 2. Descriptive statistics

\begin{tabular}{lrrrr}
\hline & Mean & SD & Minimum & Maximum \\
\hline Maximum $\mathrm{H}_{2, \text { ppm }}$ & & & & 201 \\
$\quad$ No response group & 95.78 & 46.62 & 24 & 255 \\
$\quad$ Partial response group & 104.17 & 63.21 & 14 & 255 \\
$\quad$ Total response group & 104.67 & 61.67 & 19 & 201 \\
Maximum increase, ppm & & & & 255 \\
$\quad$ No response group & 92.07 & 50.25 & 18 & 239 \\
$\quad$ Partial response group & 97.35 & 60.30 & 13 & 1,342 \\
$\quad$ Total response group & 96.16 & 57.55 & & 2,363 \\
AUC, ppm & & & & 2,674 \\
$\quad$ No response group & 577.89 & 325.25 & 43 & \\
$\quad$ Partial response group & 622.39 & 483.88 & & \\
$\quad$ Total response group & 670.13 & 487.36 & & \\
\hline
\end{tabular}

tients, no symptoms occurred during testing and 5 patients were not compliant to the diet. For 10 patients, not all data was available and 246 patients fulfilled all criteria (Fig. 2). Twenty-seven patients were non-responders, 116 were partial responders and 103 were total responders (see Table 1 for sociodemographic characteristics). Lactulose breath test revealed no false non-responders. Preliminary analysis of variance analyses showed a significant effect between age and dietary response for the 3 groups (F-val- ue $[2,243]=8.08, p<0.001$, with significant differences between the total response group and the no-response group (mean difference $[\mathrm{MD}]=-15.16, \mathrm{SD}=3.80, p<$ 0.001 ), and between the no-response group and the partial response group $(\mathrm{MD}=-10.91, \mathrm{SD}=3.76, p<0.05)$. Therefore, we controlled for age within the analyses. Descriptive statistics regarding the maximum $\mathrm{H}_{2}$ level, maximum increase in $\mathrm{H}_{2}$ and the AUC are shown in Table 2 and in Figure 4 for diarrhoea, abdominal pain and bloating. 
Fig. 3. Percentage of diarrhoea, abdominal pain and bloating (defined as percentage of patients who rated their symptoms as 2 or 3 on a scale from 0 to 3 ) per group during the $\mathrm{H}_{2}$ breath test.

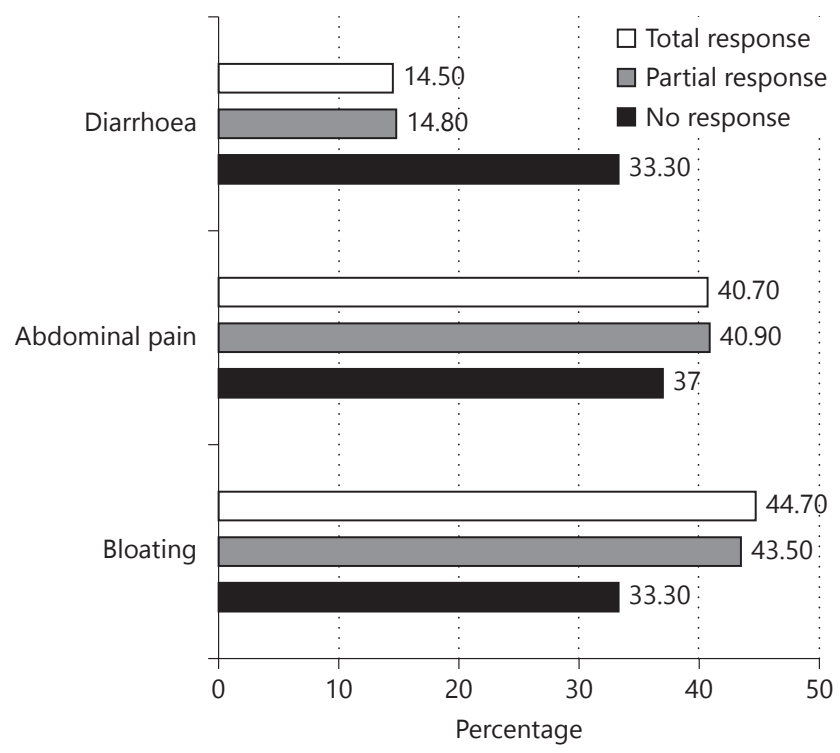

Table 3. Correlations between study variables

\begin{tabular}{lllllll}
\hline Scale & $\begin{array}{l}\text { Dietary } \\
\text { response }\end{array}$ & Bloating & $\begin{array}{l}\text { Abdominal } \\
\text { pain }\end{array}$ & Diarrhoea & $\begin{array}{l}\text { Maximum } \\
\mathrm{H}_{2}\end{array}$ & $\begin{array}{l}\text { Maximum } \\
\text { increase }\end{array}$ \\
\hline Dietary response & - & & & & \\
Bloating & 0.03 & & & & \\
Abdominal pain & 0.03 & $0.26^{* * *}$ & & & & \\
Diarrhoea & $0.13^{*}$ & $0.20^{* *}$ & $0.30^{* * *}$ & & & \\
Maximum $\mathrm{H}_{2}$ & -0.02 & $0.15^{*}$ & 0.12 & $0.23^{* * *}$ & & \\
Maximum increase & -0.01 & $0.15^{*}$ & 0.11 & $0.25^{* * *}$ & $0.98^{* * *}$ & $0.88^{* * *}$ \\
AUC & -0.05 & $0.17^{*}$ & $0.19^{* *}$ & $0.22^{* * *}$ & $0.93^{* * *}$ & 0.006 \\
\hline
\end{tabular}

${ }^{*} p<0.05 ;{ }^{* *} p<0.01 ;{ }^{* * *} p<0.001 ;(n=246)$.

AUC, area under the curve.

\section{Testing of the Hypotheses}

Our first research question was to evaluate whether the $\mathrm{H}_{2}$ breath test results predict dietary response. Ordinal regression analyses revealed that the $\mathrm{H}_{2}$ breath test had no predictive value on dietary response. Neither the total maximum, nor the maximum increase, nor the AUC predicted dietary response. Figure 3 shows the mean ppm trajectories for the 3 dietary response groups during the course of the $13 \mathrm{H}_{2}$ breath test time points.

Our second research question was to evaluate whether the $\mathrm{H}_{2}$ breath test results correlate with the symptoms of fructose malabsorption. Spearman correlation analyses showed, that diarrhoea and bloating were significantly correlated to all 3 measures of the $\mathrm{H}_{2}$ breath test (all $p<$ $0.05)$, whereas abdominal pain was correlated only with the AUC (Table 3).

Our third research question was to evaluate whether the significance value of $20 \mathrm{ppm}$ is the most adequate cutoff value. We therefore tested whether cut-off values of 40 and $60 \mathrm{ppm}$ might have a higher predictive value than $20 \mathrm{ppm}$. Repetition of the ordinal regression analyses using 40 and $60 \mathrm{ppm}$ as cut-off values revealed that there was no significant predictive value of the $\mathrm{H}_{2}$ breath test for either of these. Neither the total maximum, nor the maximum increase, nor the AUC predicted dietary response (data not shown). 


\section{Discussion}

The present study answered 3 main questions: First, regression analyses showed that the $\mathrm{H}_{2}$ breath test did not predict response to a 10-day fructose-free diet. Second, the symptoms of fructose malabsorption - diarrhoea, abdominal pain and bloating - correlated significantly to $\mathrm{H}_{2}$ breath test measures. Diarrhoea had an especially strong relationship to the $\mathrm{H}_{2}$ breath test measures. Third, cut-off values of 40 and $60 \mathrm{ppm}$ did not have a higher predictive value than the 20 ppm cut-off-value on patients' response to the fructose-free diet. Therefore, our results show a low predictive value of the $\mathrm{H}_{2}$ breath test in predicting response to a fructose-free diet. These findings are in line with the findings of previous studies that showed that $\mathrm{H}_{2}$ breath tests can only be used to detect or exclude fructose malabsorption [11]. However, in our sample, diarrhoea shows a strong correlation to $\mathrm{H}_{2}$ breath test measures. Within the study by Symons et al. [11], diarrhoea was not among the symptoms recorded. The simultaneous evaluation of $\mathrm{H}_{2}$ breath test measures and diarrhoea as a symptom might yield additional value in diagnosing fructose malabsorption. Furthermore, when diagnosing primary fructose malabsorption, it is important to exclude patients with other causes for gastrointestinal disorders such as ulcerative colitis, Crohn's disease or celiac disease. While the diagnosis for most of these diseases is often unambiguous, in a subgroup of patients, a clear cause for the symptoms cannot be detected using the diagnostic standard procedures. These patients frequently fulfil the criteria of irritable bowel syndrome (IBS).

Diarrhoea, abdominal pain and bloating are commonly experienced by patients with IBS. Provocation studies, where fructose is ingested by patients with fructose malabsorption, induce symptoms more easily in subjects with IBS than in those without $[12,13]$, pointing to the fact that fructose has an unspecific impact rather than a specific effect in this set of patients.

Furthermore, we found that younger patients had a significantly better response to the fructose-free diet, while there was no difference in the adherence to the diet. Since young age is a risk factor for being affected by a post-infectious IBS [14], it might be the case that the younger patients in our patient cohort also were affected by IBS.

A fructose-reduction diet influences the intraluminal microbiota [15-17], which is discussed as a co-factor in the pathophysiology in a subgroup of patients with IBS $[18,19]$. In our group of patients, diarrhoea was the most prevalent symptom in the no-response-group dur-

The Predictive Value of the Hydrogen Breath Test

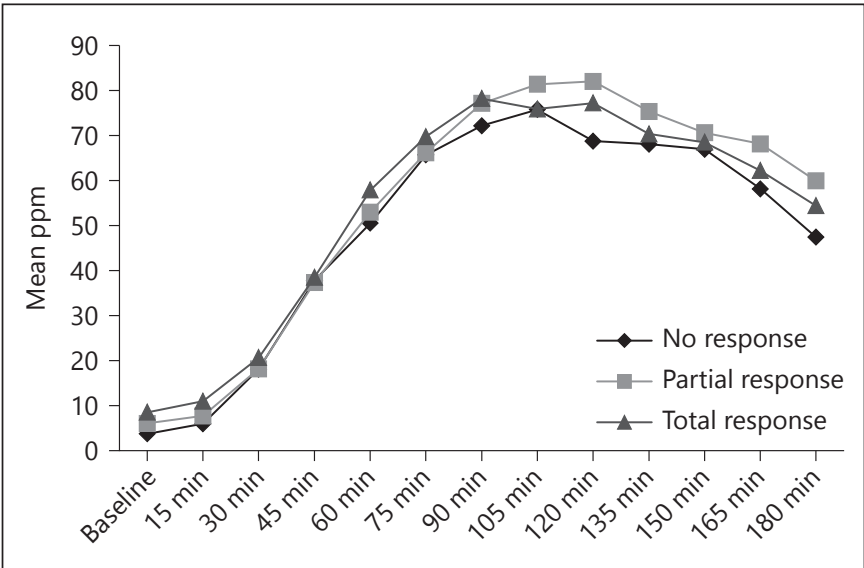

Fig. 4. Trajectories of hydrogen parts per million (ppm) for the 3 dietary response groups no response, partial response, and total response during the course of the 13 test time points.

ing the application of fructose. In addition, a fructoserestricted diet like the FODMAP (Fermentable Oligo-, Di-, Mono-Saccharides and Polyols) diet in general has shown a significant improvement of symptoms in patients with IBS [20]. The fructose-induced distension of the colon is especially reduced after a FODMAP diet [20]. The distension of the colon plays a crucial role in the pathophysiology of IBS [21-24], but is not associated with a positive $\mathrm{H}_{2}$ breath test [20]. If the bowel distension after fructose exposure is independent of the production of $\mathrm{H}_{2}$ in IBS patients, again, fructose must be rated as an unspecific rather than a specific stimulus for the symptoms induced.

In conclusion, the $\mathrm{H}_{2}$ breath test did not predict the response to a 10-day fructose-free diet. Although symptoms of fructose malabsorption correlated significantly to the $\mathrm{H}_{2}$ breath test measures, higher cut-off values of 40 and $60 \mathrm{ppm}$ did not give a higher predictive value of patients' response to the fructose-free diet than the $20 \mathrm{ppm}$ cut-off-value. Therefore, our results show a low predictive value of the $\mathrm{H}_{2}$ breath test in predicting response to a fructose-free diet. Only the fact that symptoms and the $\mathrm{H}_{2}$ breath test measures correlated significantly gives a little evidence for the predictive value of the test.

\section{Strengths and Limitations}

When studying fructose malabsorption, the choice of dosage is critical. Previous studies have shown the frequency of fructose malabsorption in healthy volunteers to be $50 \%$ up to $80 \%$ if tested with 25 or $50 \mathrm{~g}$ of fructose respectively. Studies show that a high percentage of 
healthy people have a positive $\mathrm{H}_{2}$ breath test when tested with $50 \mathrm{~g}$ fructose $[25,26]$. Because (1) of an overlap between fructose malabsorption with IBS [27], (2) the good clinical response in the case of fructose malabsorption and (3) to avoid false negative testing. Convenience food has often an underestimated content of fructose. For example, a cinema food and drink snack with a medium size Coke $(500 \mathrm{~mL})$ and medium size Popcorn $(250 \mathrm{~g})$ contains more than $50 \mathrm{~g}$ fructose [28]. Therefore, we decided to investigate patients with $50 \mathrm{~g}$ fructose as a pretest and to define the fructose malabsorption in those patients who responded to the fructose restricted diet. We tested with $50 \mathrm{~g}$ and identified $66.5 \%$ of the patients who were positive for fructose malabsorption. This conforms to other studies that wanted to avoid false negative malabsorption test results due to testing with $25 \mathrm{~g}$ fructose [29]. After the fructose-free diet, $41.9 \%$ of the diagnosed patients were complete responders, $47.2 \%$ were partial responders and $11 \%$ were non-responders. Therefore, the majority of the patients showed an improvement of symptoms after the fructose-free diet, which further confounds the validity of testing with $50 \mathrm{~g}$ fructose. These high-rate findings are congruent with findings of other groups [27, 30, 31]. But, a dosage of 50 $\mathrm{g}$ fructose might lead to a substantial amount of false positive respondents. Patients who did not show clinical symptoms of fructose malabsorption (i.e., bloating, diarrhoea or abdominal pain) therefore were identified as false positive responders and excluded from the analysis (Fig. 2). However, as a significant proportion of the population produce methane gas and many of these patients have very low $\mathrm{H}_{2}$ concentrations, it cannot be ruled out that at least some patients were nonetheless false negative patients. In our clinical observation, we found $18 \%$ $\mathrm{H}_{2}$ non responder. In our daily practice, all patients with unclear diagnostic parameters (including the non-responders) were advised to carry out a nutrition protocol. Then we performed the dietician advice based on the protocol. This was a very heterogeneous group and in the retrospective way it was not possible to use them as a control group.

Furthermore, a 4-point scale was used to determine the severity of bloating, abdominal pain and diarrhoea during the $\mathrm{H}_{2}$ breath test. This was not a validated scale, which is another limitation to this study.

To conclude, the findings of the present study support the low specificity of the fructose $\mathrm{H} 2$ breath test and lead to the necessity to confirm diagnosis by response to a fructose-free diet. Future research is necessary to confirm our findings.

\section{Study Highlights}

What is Current Knowledge?

- In fructose malabsorption, fructose is poorly absorbed in the small intestine. When fructose enters the colon fermentation, it leads to an increase of colonic gas with intestinal symptoms like bloating, pain and diarrhoea.

- The $\mathrm{H}_{2}$ breath test is a common method used to detect fructose malabsorption, which is a high prevalence disorder in healthy subjects without symptoms, leading to a low specificity of the test.

- A fructose-restricted diet often leads to a positive clinical improvement in those tested but not in all patients.

New Findings

- The $\mathrm{H}_{2}$ breath test did not predict response to a 10-day fructose-free diet.

- The symptoms of fructose malabsorption: diarrhoea, abdominal pain and bloating were significantly correlated to $\mathrm{H}_{2}$ breath test measures.

- Cut-off values of 40 and 60 ppm did not have a higher predictive value on patients' response to the fructosefree diet than $20 \mathrm{ppm}$.

- Even when there is a high prevalence of fructose malabsorption and when the fructose $\mathrm{H}_{2}$ breath test is performed with $50 \mathrm{~g}$ fructose, over $90 \%$ of the patients respond to a fructose-free diet.

\section{Disclosure Statement}

U.H.: Lecture and consulting fees: AbbVie, MSD, Ferring, Falk Foundation, Takeda, Mundipharma, Hospira, Vifor Pharma. A.K.K., N.K., and S.H.: no disclosures. J.H.: Research support: Repha; TechLab, Steigerwald, Falk Foundation. Lectures and consulting fees: Falk; MSD; Repha; Ardeypharm.

\section{References}

1 Choi YK, Johlin FC Jr, Summers RW, Jackson M, Rao SS: Fructose intolerance: an underrecognized problem. Am J Gastroenterol 2003;98:1348-1353.

2 Sibley E: Carbohydrate intolerance. Curr Opin Gastroenterol 2004;20:162-167.

3 Truswell AS, Seach JM, Thorburn AW: Incomplete absorption of pure fructose in healthy subjects and the facilitating effect of glucose. Am J Clin Nutr 1988;48:14241430.

4 Wright EM, Martin MG, Turk E: Intestinal absorption in health and disease - sugars. Best Pract Res Clin Gastroenterol 2003;17:943956
Helwig/Koch/Koppka/Holtmann/ Langhorst 
5 Barrett JS, Gearry RB, Muir JG, Irving PM, Rose R, Rosella O, Haines ML, Shepherd SJ, Gibson PR: Dietary poorly absorbed, short-chain carbohydrates increase delivery of water and fermentable substrates to the proximal colon. Aliment Pharmacol Ther 2010;31:874-882.

6 Ong DK, Mitchell SB, Barrett JS, Shepherd SJ, Irving PM, Biesiekierski JR, Smith S, Gibson PR, Muir JG: Manipulation of dietary short chain carbohydrates alters the pattern of gas production and genesis of symptoms in irritable bowel syndrome. J Gastroenterol Hepatol 2010;25:1366-1373.

7 Born P: Carbohydrate malabsorption in patients with non-specific abdominal complaints. World J Gastroenterol 2007;13:56875691.

8 Duan LP, Braden B, Clement T, Caspary WF, Lembcke B: Clinical evaluation of a miniaturized desktop breath hydrogen analyzer. $\mathrm{Z}$ Gastroenterol 1994;32:575-578.

9 Fleming SC: Evaluation of a hand-held hydrogen monitor in the diagnosis of intestinal lactase deficiency. Ann Clin Biochem 1990;27(Pt 5):499-500.

10 Rana SV, Malik A: Breath tests and irritable bowel syndrome. World J Gastroenterol 2014; 20:7587-7601.

11 Symons P, Jones MP, Kellow JE: Symptom provocation in irritable bowel syndrome. Effects of differing doses of fructose-sorbitol. Scand J Gastroenterol 1992;27:940-944.

12 Fernandez-Banares F, Esteve-Pardo M, de Leon R, Humbert P, Cabre E, Llovet JM, Gassull MA: Sugar malabsorption in functional bowel disease: clinical implications. Am J Gastroenterol 1993;88:2044-2050.

13 Nelis GF, Vermeeren MA, Jansen W: Role of fructose-sorbitol malabsorption in the irritable bowel syndrome. Gastroenterology 1990; 99:1016-1020.

14 Spiller R, Garsed K: Postinfectious irritable bowel syndrome. Gastroenterology 2009;136: 1979-1988.
15 Chumpitazi BP, Cope JL, Hollister EB, Tsai CM, McMeans AR, Luna RA, Versalovic J, Shulman RJ: Randomised clinical trial: gut microbiome biomarkers are associated with clinical response to a low fodmap diet in children with the irritable bowel syndrome. Aliment Pharmacol Ther 2015;42:418-427.

16 Staudacher HM, Whelan K: Altered gastrointestinal microbiota in irritable bowel syndrome and its modification by diet: probiotics, prebiotics and the low fodmap diet. Proc Nutr Soc 2016;75:306-318.

17 Wu GD, Chen J, Hoffmann C, Bittinger K, Chen YY, Keilbaugh SA, Bewtra M, Knights D, Walters WA, Knight R, Sinha R, Gilroy E, Gupta K, Baldassano R, Nessel L, Li H, Bushman FD, Lewis JD: Linking long-term dietary patterns with gut microbial enterotypes. Science 2011;334:105-108.

18 Kassinen A, Krogius-Kurikka L, Makivuokko $\mathrm{H}$, Rinttila T, Paulin L, Corander J, Malinen E, Apajalahti J, Palva A: The fecal microbiota of irritable bowel syndrome patients differs significantly from that of healthy subjects. Gastroenterology 2007;133:24-33.

19 Lee BJ, Bak YT: Irritable bowel syndrome, gut microbiota and probiotics. J Neurogastroenterol Motil 2011;17:252-266.

20 Murray K, Wilkinson-Smith V, Hoad C, Costigan C, Cox E, Lam C, Marciani L, Gowland P, Spiller RC: Differential effects of FODMAPS (fermentable oligo-, di-, monosaccharides and polyols) on small and large intestinal contents in healthy subjects shown by MRI. Am J Gastroenterol 2014;109:110119.

21 Agrawal A, Houghton LA, Lea R, Morris J, Reilly B, Whorwell PJ: Bloating and distention in irritable bowel syndrome: the role of visceral sensation. Gastroenterology 2008; 134:1882-1889.

22 Bouin M, Plourde V, Boivin M, Riberdy M, Lupien F, Laganiere M, Verrier P, Poitras P: Rectal distention testing in patients with ir- ritable bowel syndrome: Sensitivity, specificity, and predictive values of pain sensory thresholds. Gastroenterology 2002; 122: 1771-1777.

23 Ritchie J: Pain from distension of the pelvic colon by inflating a balloon in the irritable colon syndrome. Gut 1973;14:125-132.

24 Tremolaterra F, Villoria A, Azpiroz F, Serra J Aguade S, Malagelada JR: Impaired viscerosomatic reflexes and abdominal-wall dystony associated with bloating. Gastroenterology 2006; 130:1062-1068.

25 Frieling T, Kuhlbusch-Zicklam R, Kalde S, Heise J, Hulsdonk A, Kreysel C: Fructose malabsorption: how much fructose can a healthy subject tolerate? Digestion 2011;84: 269-272.

26 Rao SS, Attaluri A, Anderson L, Stumbo P: Ability of the normal human small intestine to absorb fructose: evaluation by breath testing. Clin Gastroenterol Hepatol 2007;5:959963.

27 Goldstein R, Braverman D, Stankiewicz H: Carbohydrate malabsorption and the effect of dietary restriction on symptoms of irritable bowel syndrome and functional bowel complaints. Isr Med Assoc J 2000;2:583-587.

28 Souci SW, Fachmann W, Kraut H: Food Composition and Nutrition Tables. MedPharm Scientific Publications, 2008.

29 Goebel-Stengel M, Monnikes H: Optimal testing for diagnosis of fructose malabsorption: Under-dosage leads to false negative intolerance test. J Neurogastroenterol Motil 2015;21:296-297.

30 Born P, Vierling T, Paul F: Effect of diet in symptomatic patients with fructose malabsorption. Eur J Gastroenterol and Hepatology 1994;6:701-704.

31 Dabritz J, Muhlbauer M, Domagk D, Voos N, Hennebohl G, Siemer ML, Foell D: Significance of hydrogen breath tests in children with suspected carbohydrate malabsorption. BMC Pediatr 2014;14:59.
The Predictive Value of the Hydrogen Breath Test
Digestion 2019;99:140-147

DOI: $10.1159 / 000489877$ 


\section{DuEPublico}

Duisburg-Essen Publications online
DESISB B R G

offen im Denken

This text is made available via DuEPublico, the institutional repository of the University of Duisburg-Essen. This version may eventually differ from another version distributed by a commercial publisher.

DOI: $\quad 10.1159 / 000489877$

URN: urn:nbn:de:hbz:464-20201123-162847-2

This publication is with permission of the rights owner freely accessible due to an Alliance licence and a national licence (funded by the DFG, German Research Foundation) respectively.

All rights reserved. 